\title{
Renal impairment in cirrhosis unrelated to hepatorenal syndrome
}

\author{
Gavin Low MBChB MRCS FRCR ${ }^{1,3}$, Graeme JM Alexander MD FRCP², David J Lomas MA MB BChir FRCP FRCR ${ }^{1}$
}

\author{
G Low, GJM Alexander, DJ Lomas. Renal impairment in cirrhosis \\ unrelated to hepatorenal syndrome. Can J Gastroenterol Hepatol \\ 2015;29(5):253-257.
}

Renal impairment is common in liver disease and may occur as a consequence of the pathophysiological changes that underpin cirrhosis or secondary to a pre-existing unrelated insult. Nevertheless, the onset of renal impairment often portends a worsening prognosis. Hepatorenal syndrome remains one of the most recognized and reported causes of renal impairment in cirrhosis. However, other causes of renal impairment occur and can be classified into prerenal, intrinsic or postrenal, which are the subjects of the present review.

Key Words: Acute kidney injury; Cirrhosis; Intrinsic renal impairment; Postrenal impairment; Prerenal impairment
Patients with cirrhosis are susceptible to renal impairment as a result exposure to precipitating factors. Hampel et al (1) found that acute renal impairment occurred in $24.7 \%$ (23 of 96) of hospitalized patients with cirrhosis. In an intensive care unit setting, the incidence of acute renal impairment in cirrhotic patients was reported to be $15.1 \%$ (144 of 932) by Peron et al (2) and 39.2\% (73 of 186) by du Cheyron et al (3). Terra et al (4) found that 27\% (29 of 106) of cirrhotic patients with sepsis unrelated to spontaneous bacterial peritonitis (SBP) developed renal impairment compared with only $8 \%$ (eight of 100) of those without infection. Combining the findings of the four aforementioned studies, Garcia-Tsao et al (5) calculated that acute renal impairment occurred in approximately $19 \%$ of patients with cirrhosis. In contrast, chronic renal failure is present in $1 \%$ of individuals with cirrhosis (5). A variety of etiologies are implicated in the development of renal impairment (Figure 1). These have an impact on clinical presentation, treatment options and prognosis. In a prospective study investigating 562 consecutive patients with cirrhosis and renal impairment (6), three-month survival was $73 \%$ for intrinsic renal impairment, $46 \%$ for hypovolemia-induced prerenal impairment, $31 \%$ for infection-related renal impairment and $15 \%$ for hepatorenal syndrome (HRS). The onset of renal impairment in cirrhosis is an important prognostic indicator $(7-12)$. A systematic review of 118 studies by D'Armico et al (10) found that measures of renal impairment (serum creatinine, blood urea nitrogen/azotemia) were strong predictors of mortality in decompensated cirrhosis. In a systematic review of 74 studies, Fede et al (11) found that cirrhotic patients with renal impairment had a $>7$-fold increased risk for death within one year compared with cirrhotic patients without renal impairment. The one-month and 12-month mortality for patients with renal impairment other than HRS were $56 \%$ and $36 \%$, respectively. Renal impairment correlated with death on univariate analysis in 29 studies and on multivariate analysis in 13 studies (11). When serum creatinine was evaluated, it correlated with death on univariate analysis in 16 studies and on multivariate analysis in two studies (11). Serum creatinine level is a variable in

\section{Une atteinte rénale causée par la cirrhose, mais non liée au syndrome hépatorénal}

L'atteinte rénale est courante dans le contexte d'une maladie hépatique. Elle peut découler des changements physiopathologiques de la cirrhose ou d'un problème préexistant non lié. Elle sous-tend souvent un pronostic plus sombre. Le syndrome hépatorénal demeure l'une des causes d'atteinte rénale les plus connues et les plus signalées en cas de cirrhose. La présente analyse porte sur les autres causes possibles, qui sont d'étiologie pré-rénale, intrinsèque ou post-rénale.

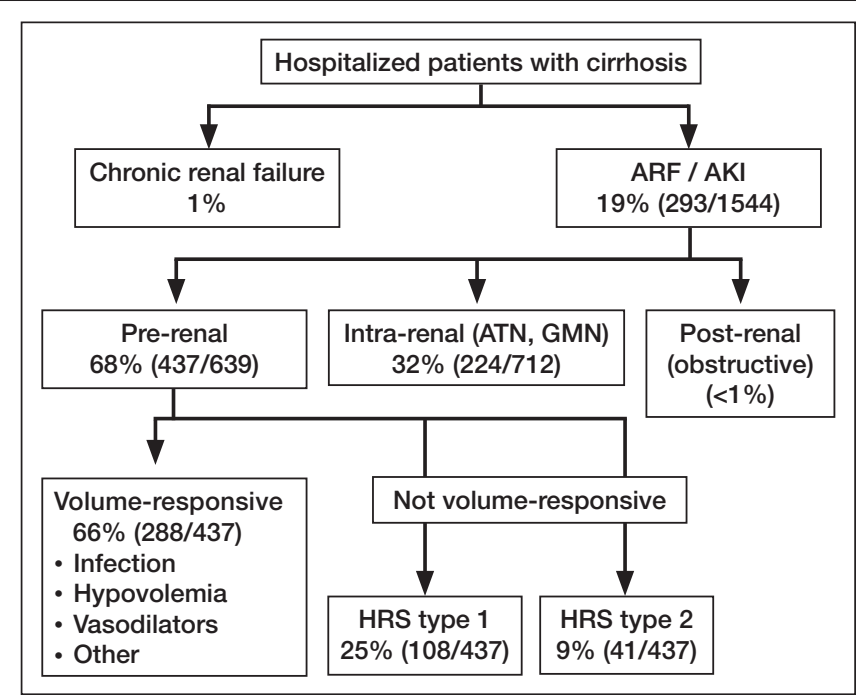

Figure 1) Types of renal impairment in hospitalized patients with cirrhosis. AKI Acute kidney injury; ARF Acute renal failure; ATN Acute tubular necrosis; GMN Glomerulonephritis; HRS Hepatorenal syndrome. Adapted and reproduced with permission from reference 5

calculating the Model for End-stage Liver Disease score - a recognized predictor of the three-month mortality risk and a method used for allocating liver transplants $(13,14)$.

Traditionally, renal failure is defined by a serum creatinine threshold of $\geq 1.5 \mathrm{mg} / \mathrm{dL}(\geq 133 \mu \mathrm{mol} / \mathrm{L})$. However, serum creatinine is not a reliable marker of renal function in cirrhosis because a normal serum creatinine level does not exclude mild disease. Cirrhotic patients may show a lower baseline serum creatinine level than normal due to: reduced endogenous creatinine synthesis from liver dysfunction; decreased conversion of creatine to creatinine as a consequence of

${ }^{1}$ Department of Radiology; 2Division of Gastroenterology Eु Hepatology, Addenbrooke's Hospital, Cambridge University Hospitals NHS Foundation Trust, United Kingdom; ${ }^{3}$ University of Alberta, Edmonton, Alberta

Correspondence: Dr Gavin Low, University of Cambridge School of Clinical Medicine, Box 218, Cambridge Biomedical Campus, Cambridge,

CB2 0QQ United Kingdom. Telephone 01223 336890, fax 01223 330915, e-mail timgy@yahoo.com

Received for publication June 30, 2014. Accepted January 12, 2015 


TABLE 1
Acute Kidney Injury Network classification of acute kidney
injury (AKI)
\begin{tabular}{l} 
AKI stage $\quad$ Serum creatinine criteria \\
\hline $1 \quad$ Increase in serum creatinine level $\geq 26.4 \mu \mathrm{mol} / \mathrm{L}(\geq 0.3 \mathrm{mg} / \mathrm{dL})$ \\
within 48 h or an increase $\geq 150 \%$ to $200 \%(1.5$ - to twofold $)$ \\
from baseline \\
Increase in serum creatinine level to $>200 \%$ to $300 \%$ \\
( $>2-3-$ fold) from baseline \\
Increase in serum creatinine level to $>300 \%(>3-f o l d)$ from \\
baseline or serum creatinine $\geq 354 \mu \mathrm{mol} / \mathrm{L}(\geq 4.0 \mathrm{mg} / \mathrm{dL})$ with \\
an acute increase of $\geq 44 \mu \mathrm{mol} / \mathrm{L}(\geq 0.5 \mathrm{mg} / \mathrm{dL})$ or initiation of \\
renal replacement therapy
\end{tabular}

Reproduced and adapted from reference 20

\section{TABLE 2}

\section{Revised diagnostic criteria for hepatorenal syndrome} (International Ascites Club, 2007)

\section{- Cirrhosis with ascites \\ - Serum creatinine $>133 \mu \mathrm{mol} / \mathrm{L}(1.5 \mathrm{mg} / \mathrm{dL})$ \\ - No improvement in serum creatinine (decrease to a level of $\leq 133 \mu \mathrm{mol} / \mathrm{L}$ ) after $\geq 2$ days with diuretic withdrawal and volume expansion with albumin. The recommended dose of albumin is $1 \mathrm{~g} / \mathrm{kg}$ of body weight/day up to a maximum of $100 \mathrm{~g} /$ day \\ - Absence of shock \\ - No current or recent treatment with nephrotoxic drugs \\ - Absence of parenchymal kidney disease as indicated by proteinuria $>500 \mathrm{mg} /$ day, microscopic hematuria (>50 red blood cells per high-power field) and/or abnormal renal ultrasonography}

Reproduced with permission from reference 24

reduced skeletal muscle mass from malnutrition; drug-related increased tubular secretion of creatinine; and laboratory-based underestimations of serum creatinine in the setting of hyperbilirubinemia (15). Cystatin C is an alternative method for estimating the glomerular filtration rate (GFR). It may be more accurate than serum creatinine in cirrhotic patients because cystatin $\mathrm{C}$ is independent of hepatic function; it is not influenced by muscle mass, sex, race or diet, and tubular secretion of cystatin C is not increased in cirrhosis (16). Several cystatin C-based GFR equations have been described such as the Larsson equation, Hoek equation and Chronic Kidney Disease Epidemiology Collaboration (CKD-EPI) cystatin C equation (17-19). In a study involving 72 patients with cirrhosis, Mindikoglu et al (15) compared a combined CKD-EPI creatinine-cystatin C equation with that of $24 \mathrm{~h}$ urinary creatinine clearance, Cockcroft-Gault and other creatinineand/or cystatin C-based GFR equations (15). Using nonradiolabelled iothalamate clearance as the gold standard for measuring GFR, a significantly higher accuracy was found for the CKD-EPI creatininecystatin $\mathrm{C}$ equation compared with the other GFR-based equations. However, the study noted that the diagnostic performance of the CKD-EPI creatinine-cystatin $\mathrm{C}$ equation was worse in cirrhotic patients than in those without cirrhosis.

The definition of renal dysfunction was revised by the Acute Kidney Injury Network in 2005, and the term 'acute renal failure' was replaced by 'acute kidney injury' (AKI) (20). Table 1 describes the AKI classification and staging system. To frame AKI in the context of cirrhosis, a working group comprising members of the International Ascites Club and the Acute Dialysis Quality Initiative was formed in 2010. The working group defined AKI in cirrhosis as encompassing all causes of acute renal impairment in which the serum creatinine level increased by $\geq 50 \%$ ( $\geq 1.5$-fold) from baseline or in which the serum creatinine level rose by $\geq 26.4 \mu \mathrm{mol} / \mathrm{L}(\geq 0.3 \mathrm{mg} / \mathrm{dL})$ in $<48 \mathrm{~h}$ (21). This revised definition has higher sensitivity $(65.4 \%$ versus $53.8 \%)$ but reduced specificity $(61.8 \%$ versus $85.3 \%)$ for predicting in-hospital mortality compared with traditional criteria (22). Chronic kidney disease (CKD) in cirrhosis was defined as a GFR $<60 \mathrm{~mL} / \mathrm{min}$

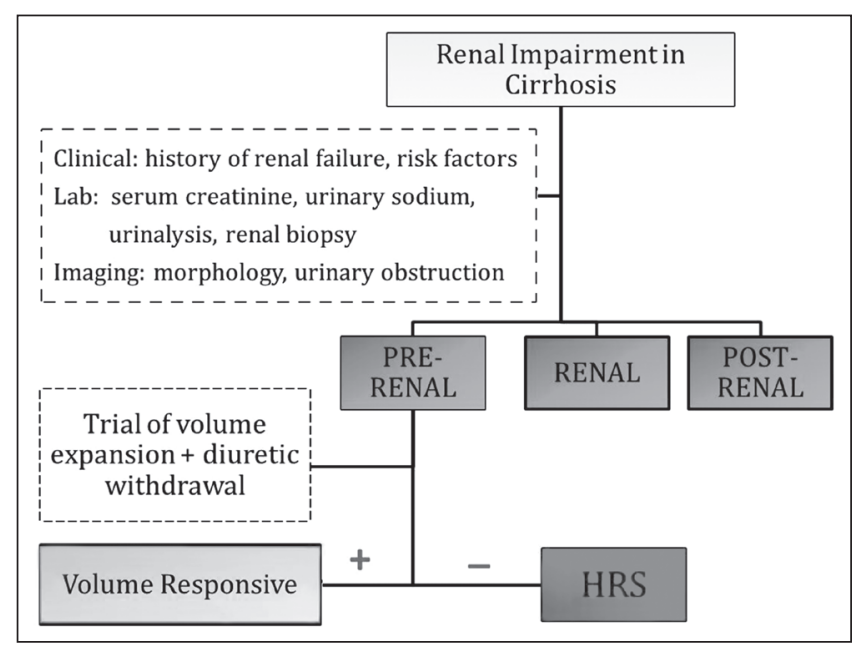

Figure 2) The authors' simplified diagnostic algorithm for the clinical work-up of renal impairment in patients with cirrhosis. HRS Hepatorenal syndrome

for $>3$ months, calculated using the Modification of Diet in Renal Diseases-6 formula (21). Finally, acute-on-CKD was defined as AKI occurring in the context of pre-existing CKD (21).

The most common causes of renal impairment in cirrhosis are hypovolemia-induced prerenal AKI, acute tubular necrosis (ATN) and HRS (5). HRS is the most lethal of these causes of renal impairment, with prognosis typically ranging from weeks to months $(14,23)$. It is a functional renal impairment due to profound renal arterial vasoconstriction precipitated by unregulated circulatory and neurohormonal alterations that underpin cirrhosis. While the topic of HRS is outside the scope of the present review, the revised diagnostic criteria for HRS is included (Table 2) because it allows HRS to be recognized and differentiated from other causes of renal impairment and vice versa (24). Type 1 HRS is a rapid, progressive, renal impairment defined by a doubling of the serum creatinine to a level $>2.5 \mathrm{mg} / \mathrm{dL}(>226 \mu \mathrm{mol} / \mathrm{L}$ ) in $<2$ weeks (24). Type 2 HRS is moderate renal impairment (serum creatinine $>1.5 \mathrm{mg} / \mathrm{dL}$ [ $>133 \mu \mathrm{mol} / \mathrm{L}]$ and up to $2.5 \mathrm{mg} / \mathrm{dL}$ [226 $\mu \mathrm{mol} / \mathrm{L}])$ with a steady progressive course that evolves over weeks to months (24). In the present article, the causes of renal impairment other than HRS, collectively termed 'non-HRS' renal impairment are discussed, which are divided into prerenal, intrinsic renal and postrenal causes. A simplified diagnostic algorithm for the clinical work-up of renal impairment in cirrhosis is illustrated in Figure 2.

\section{PRERENAL IMPAIRMENT}

Prerenal impairment is the most common type of renal dysfunction in cirrhosis, accounting for $68 \%$ of AKI cases (5), and may be due to either hypovolemia-induced prerenal impairment $(66 \%)$ or HRS (34\%) (5). Patients with cirrhosis are predisposed to develop prerenal impairment due to underlying circulatory disturbances such as arterial underfilling (that occurs as a result of splanchnic vasodilation). These pathophysiological changes are mild in hypovolemiainduced prerenal impairment, but severe in HRS, in which neurohormonal activation results in renal vasoconstriction and severely diminished renal perfusion. These two causes of prerenal impairment can be differentiated by the response to volume expansion. Hypovolemia-induced prerenal impairment responds to volume expansion with rapid normalization of renal function. Conversely, HRS is insensitive to volume expansion, with no improvement in renal function. Albumin is superior to saline for volume expansion, and the recommended dose of intravenous albumin is $1 \mathrm{~g} / \mathrm{kg}$ of body weight/day up to a maximum of $100 \mathrm{~g}$ per day $(24,25)$.

In hypovolemia-induced prerenal impairment, excessive fluid loss may be the result of various causes including vomiting, diarrhea, sodium and water restriction, gastrointestinal hemorrhage, large-volume paracentesis 
(LVP) and excessive diuretic therapy. Diarrhea may be a side effect of lactulose therapy in patients with hepatic encephalopathy. Diureticinduced prerenal impairment occurs in $15 \%$ to $25 \%$ of patients with cirrhosis and ascites (26). Nephrotoxic drugs, such as nonsteroidal anti-inflammatory drugs, angiotensin-converting enzyme inhibitors and angiotensin II inhibitors, may precipitate prerenal failure by interfering with vasoactive mechanisms that modulate renal perfusion. Infection is another significant cause of prerenal impairment and may precede septic shock. This precipitates renal impairment due to systemic vasodilation, arterial hypotension and diminished renal perfusion. Up to $10 \%$ of cases of SBP are associated with septic shock (27).

Measures should be instituted in cirrhotic patients to prevent intravascular volume depletion and, consequently, reduce the risk for prerenal impairment, including careful attention to fluid balance, judicious use of diuretics, avoidance of nephrotoxic drugs (especially nonsteroidal anti-inflammatory drugs and aminoglycoside antibiotics), avoidance of excessive lactulose therapy, administration of intravenous albumin after LVP and prompt treatment of infection. A meta-analysis of 17 randomized trials involving 1225 patients with cirrhosis and tense ascites (25) found that albumin reduced mortality and morbidity in patients undergoing LVP when compared with alternative treatments such as dextran, gelatin, hydroxyethyl starch and hypertonic saline. The incidence of postparacentesis complications, such as circulatory dysfunction (OR 0.39 [95\% CI 0.27 to 0.55]), hyponatremia (OR 0.58 [95\% CI 0.39 to 0.87]) and death (OR 0.64 [95\% CI 0.41 to 0.98]) were lower in patients who were administered albumin compared with those who underwent alternative treatments. Given the evidence, the American Association for the Study of Liver Diseases recommends that albumin infusion ( $6 \mathrm{~g} / \mathrm{L}$ to $8 \mathrm{~g} / \mathrm{L}$ of ascitic fluid removed) be performed for LVP ( $\geq 5 \mathrm{~L}$ ) but that albumin may not be necessary for a single paracentesis of $<4$ L to 5 L (28). The European Association for the Study of the Liver also recommends the use of albumin $(8 \mathrm{~g} / \mathrm{L}$ of ascitic fluid removed) after LVP ( $\geq 5 \mathrm{~L}$ ) (29). In a randomized controlled trial involving 1126 patients with cirrhosis and SBP, Sort et al (30) found that the addition of albumin to cefotaxime (antibiotic) reduced the risk of renal impairment compared with treatment by cefotaxime alone. The incidence of renal impairment was $10 \%$ in the albumin plus cefotaxime group compared with $33 \%$ in the cefotaxime only group $(\mathrm{P}=0.01)$. Furthermore, the in-hospital and three-month mortality rates were lower in the albumin plus cefotaxime group compared with the cefotaxime only group ( $10 \%$ compared with $29 \%$ [P=0.01] and $22 \%$ compared with $41 \%[\mathrm{P}=0.03])$. A more recent study involving 38 episodes of SBP in 28 patients suggested that albumin should be given when the serum creatinine level is $>88.4 \mu \mathrm{mol} / \mathrm{L}$ or bilirubin $>68.4 \mu \mathrm{mol} / \mathrm{L}$ but was not necessary in patients who did not meet this criteria (31). The American Association for the Study of Liver Diseases recommends that patients with SBP that have a serum creatinine level $>1 \mathrm{mg} / \mathrm{dL}$ $(88.4 \mu \mathrm{mol} / \mathrm{L})$, blood urea nitrogen $>30 \mathrm{mg} / \mathrm{dL}(10.7 \mathrm{mmol} / \mathrm{L})$ or total bilirubin $>4 \mathrm{mg} / \mathrm{dL}(68.4 \mu \mathrm{mol} / \mathrm{L})$ should receive $1.5 \mathrm{~g}$ of albumin per $\mathrm{kg}$ body weight within $6 \mathrm{~h}$ of detection and $1 \mathrm{~g} / \mathrm{kg}$ on day 3 (28). In contrast, the European Association for the Study of the Liver recommends that all patients that develop SBP should be treated with broad-spectrum antibiotics and albumin (29).

\section{INTRINSIC RENAL IMPAIRMENT}

Intrinsic renal impairment may be caused by abnormalities in the renal tubules (eg, ATN), the glomeruli (eg, glomerulonephritis) or interstitium (eg, interstitial nephritis). It should be suspected in patients with proteinuria $(>500 \mathrm{mg} / \mathrm{dL}[>5 \mathrm{~g} / \mathrm{L}])$ and/or hematuria ( $>50$ red cells per high-powered field). A careful review of the medical history, including comorbidities and drug history, is often helpful in achieving the correct diagnosis. Renal biopsy is reserved for indeterminate cases in which obtaining histological diagnosis may alter patient management or prognosis. Ideally, the decision to biopsy should be taken following expert consultation with a renal physician. Indications for renal biopsy in cirrhosis patients as reported by Francoz et al (32) include: abnormal duration of acute renal impairment or failure of recovery with specific therapy; acute renal impairment with suspicion of superimposed CKD in candidates for liver transplantation; suspicion of uncommon intrinsic kidney disease (systemic disease, immune-allergic-induced drug toxicity, thrombotic microangiopathy) with potential curative intervention; and candidates for liver transplantation that have CKD with a GFR of either $15 \mathrm{~mL} / \mathrm{min}$ to $30 \mathrm{~mL} / \mathrm{min}$ (systematic biopsy) or $30 \mathrm{~mL} / \mathrm{min}$ to $60 \mathrm{~mL} / \mathrm{min}$ (biopsy if suspicious for parenchymal disease as indicated by proteinuria $>500 \mathrm{mg} /$ day, microhematuria and/or a recognized cause of CKD such as hepatitis $\mathrm{C}$ virus [HCV] or hepatitis $\mathrm{B}$ virus [HBV], diabetes or history of hypertension) (32).

ATN is the most common cause of intrinsic renal impairment in patients with cirrhosis. According to separate reports, ATN accounts for $<32 \%, 41.7 \%$ and $44.4 \%$ of cases of renal impairment in cirrhosis $(5,33,34)$. ATN may be either ischemic or toxic, while the clinical course is divided into initiation (hours to weeks), maintenance (one to two weeks) and recovery stages. Hypovolemia-induced prerenal impairment may progress into ischemic ATN in severe cases. Aminoglycoside antibiotics are the most common cause of toxic ATN, and others include nonsteroidal anti-inflammatory drugs, calcineurin inhibitor immunosuppression and radioiodine contrast agents. While radioiodine contrast agents are safe in patients with normal renal function, those with borderline renal function are at an increased risk for nephrotoxicity. In a prospective study involving 404 patients with cirrhosis, Prakash et al (34) found that precipitating factors for ATN included sepsis (most commonly SBP followed by urinary tract infection) in $61.4 \%$, hypovolemia (most commonly gastrointestinal bleed followed by septic shock) in $36.4 \%$ and nephrotoxic drugs in $2.3 \%$. In ATN, the tubular ability to reabsorb sodium and concentrate urine is impaired, leading to high urinary sodium (> $40 \mathrm{mEq} / \mathrm{L})$, high fractional excretion of sodium $(2 \%)$ and low urinary osmolality $(<350 \mathrm{mOsm} / \mathrm{kg})(5)$. Conversely, patients with HRS have low urinary sodium $(<20 \mathrm{mEq} / \mathrm{L})$, low fractional excretion of sodium $(<1 \%)$ and elevated urinary osmolality $(>500 \mathrm{mOsm} / \mathrm{kg})$ (5). Nevertheless, differentiation can be challenging in patients with cirrhosis because diuretic therapy can lead to a urinary sodium $>10 \mathrm{mEq} / \mathrm{L}$ while a fractional sodium excretion $\leq 1 \%$ is occasionally found in ATN (5). Granular casts may be found in both ATN and HRS, but epithelial casts favour ATN $(5,35)$.

Chronic HBV and HCV cirrhosis are associated with a variety of glomerular diseases such as membranoproliferative glomerulonephritis (most common glomerular disease induced by HCV) with or without cryoglobulinemia, membranous nephropathy (most common glomerular disease induced by HBV) and focal glomerulosclerosis $(36,37)$. Abnormalities of immunoglobuilin (Ig)A have been reported in patients with alcohol-related cirrhosis, including mesangial IgA deposits and development of secondary $\operatorname{IgA}$ nephropathy $(38,39)$. Elevated circulating serum IgA is common in patients with alcoholrelated liver disease, while mesangial IgA renal deposits are reported at autopsy in $36 \%$ of those with cirrhosis $(40,41)$. Interstitial nephritis is most commonly due to drug-induced hypersensitivity reactions. Renal impairment may also be due to comorbidities, such as diabetes and atherosclerosis, which may lead to diabetic nephropathy and atherosclerotic-related glomerulosclerosis. Studies suggest that a significant proportion of cirrhotic patients have underlying atherosclerotic disease, as noted by the high incidence of coronary artery disease $(20 \%$ to $25 \%)$ in this cohort $(32,42,43)$. Letiexhe et al $(44)$ reported that the incidence of diabetes may be as high as $25 \%$ in HCV cirrhosis. The clinical diagnosis of diabetic nephropathy is dependent on the detection of albuminuria and declining renal function. Albuminuria is diagnosed based on abnormal findings in two of three urine samples collected over a three- to six-month period. Depending on the urinary albumin excretion rate, it is staged as either microalbuminuria $(30 \mathrm{mg} / 24 \mathrm{~h}$ to $299 \mathrm{mg} / 24 \mathrm{~h})$ or macroalbuminuria $(\geq 300 \mathrm{mg} / 24 \mathrm{~h})$ $(45,46)$. In a diabetic patient with cirrhosis, differentiating diabetic nephropathy from other causes of intrinsic renal impairment is often challenging. Patients may have multiple risk factors for renal impairment 
(eg, diabetes, hypertension, $\mathrm{HCV}$, etc), more than one type of renal disease may exist concurrently, while nondiabetic renal disease may be found in diabetic patients (47-51). Findings that are regarded as suspicious for a nondiabetic cause of intrinsic renal impairment in a diabetic patient include: hematuria; absence of coexisting diabetic retinopathy; nephrotic range proteinuria $(3.5 \mathrm{~g} / 24 \mathrm{~h})$ in patients with diabetes $<5$ years in duration; active urinary sediment; and rapid deterioration of GFR in patients with previously stable renal function (49-52). In such cases, a renal biopsy may be performed to obtain histological diagnosis (52).

\section{POSTRENAL IMPAIRMENT}

Postrenal impairment due to urinary tract obstruction is an uncommon cause of renal dysfunction, accounting for $<1 \%$ of AKI cases in cirrhosis and $5 \%$ to $10 \%$ of AKI cases in the general population (5,53-55). The presence of hydronephrosis on imaging differentiates postrenal from prerenal or intrinsic renal causes of kidney dysfunction. Ultrasound is used most often to assess for hydronephrosis because it is widely available, portable, inexpensive and free from ionizing radiation. Computed tomography and magnetic resonance imaging may be performed in cases in which the ultrasound examination is incomplete or to re-evaluate equivocal sonographic findings. Urinary tract obstruction has many causes. In a retrospective study of 888 patients admitted to intensive care from 1998 to 2010, Hamdi et al (53) found that malignancy represented one-half of all causes of postrenal AKI. Prostate cancer was the most common malignancy (55\%) while pelvic cancers as a group accounted for $90 \%$ of all malignancies. Other causes of postrenal impairment include benign prostatic hypertrophy $(21 \%)$, urinary tract calculi (10\%) and, less often, retroperitoneal fibrosis, urethral stricture, postradiation ureteritis, bladder dysfunction and papillary necrosis. Resolution of acute urinary tract obstruction may be associated with

\section{REFERENCES}

1. Hampel H, Bynum GD, Zamora E, El-Serag HB. Risk factors for the development of renal dysfunction in hospitalized patients with cirrhosis. Am J Gastroenterol 2001;96:2206-10.

2. Peron JM, Bureau C, Gonzalez L, et al. Treatment of hepatorenal syndrome as defined by the international ascites club by albumin and furosemide infusion according to the central venous pressure: A prospective pilot study. Am J Gastroenterol 2005;100:2702-7.

3. du Cheyron D, Bouchet B, Parienti JJ, Ramakers M, Charbonneau P. The attributable mortality of acute renal failure in critically ill patients with liver cirrhosis. Intens Care Med 2005;31:1693-9.

4. Terra C, Guevara M, Torre A, et al. Renal failure in patients with cirrhosis and sepsis unrelated to spontaneous bacterial peritonitis: Value of MELD score. Gastroenterology 2005;129:1944-53.

5. Garcia-Tsao G, Parikh CR, Viola A. Acute kidney injury in cirrhosis. Hepatology (Baltimore, Md) 2008;48:2064-77.

6. Martin-Llahi M, Guevara M, Torre A, et al. Prognostic importance of the cause of renal failure in patients with cirrhosis. Gastroenterology 2011;140:488-96,e4.

7. de Carvalho JR, Villela-Nogueira CA, Luiz RR, et al. Acute Kidney Injury Network criteria as a predictor of hospital mortality in cirrhotic patients with ascites. J Clin Gastroenterol 2012;46:e21-6.

8. Lopes JA, Melo MJ, Costa AC, et al. Acute kidney injury and in-hospital mortality in critically ill patients with cirrhosis: A cohort study. Gut 2012;61:955-6.

9. Weismuller TJ, Prokein J, Becker T, et al. Prediction of survival after liver transplantation by pre-transplant parameters. Scand J Gastroenterol 2008;43:736-46.

10. D'Amico G, Garcia-Tsao G, Pagliaro L. Natural history and prognostic indicators of survival in cirrhosis: A systematic review of 118 studies. J Hepatol 2006;44:217-31.

11. Fede G, D'Amico G, Arvaniti V, et al. Renal failure and cirrhosis: A systematic review of mortality and prognosis. J Hepatol 2012;56:810-8.

12. Belcher JM, Garcia-Tsao G, Sanyal AJ, et al. Association of AKI with mortality and complications in hospitalized patients with cirrhosis. Hepatology (Baltimore, Md) 2013;57:753-62.

13. Kamath PS, Kim WR. The model for end-stage liver disease (MELD). Hepatology (Baltimore, Md) 2007;45:797-805. postobstructive diuresis (POD) as defined by a urine output $>4 \mathrm{~L}$ per day. Close monitoring is required during this stage because excessive urinary losses can lead to hypovolemia and electrolyte disturbance. Hamdi et al (53) reported that $63 \%$ of intensive care patients with severe postrenal AKI had POD following release of urinary obstruction. The authors found that POD occurrence was predictive of renal recovery while the absence of POD was predictive of CKD. Predictors of POD occurrence before release of urinary obstruction were a higher serum creatinine concentration, a higher serum bicarbonate concentration and the presence of urinary retention $(\mathrm{P}<0.05)$. Predictors of CKD included lower blood hemoglobin and serum bicarbonate concentrations on admission, a longer time from admission to the release of urinary obstruction and the absence of POD $(\mathrm{P}<0.05)$.

\section{CONCLUSION}

Renal impairment in patients with cirrhosis unrelated to hepatorenal syndrome encompasses prerenal, intrinsic and postrenal causes. Regardless of etiology, the development of renal impairment in cirrhosis is a marker of poor patient outcome. Hypovolemiainduced prerenal impairment can be differentiated from HRS because only the former shows a response to volume replacement. Intrinsic renal impairment should be suspected in patients with hematuria and/or proteinuria. The presence of hydronephrosis indicates a postrenal cause of the renal impairment.

GRANT SUPPORT: NIHR CBRC funding (National Institute of Health Research UK, Cambridge Biomedical Research Centre).

DISCLOSURES: The authors have no financial disclosures or conflicts of interest to declare.
14. Alessandria C, Ozdogan O, Guevara M, et al. MELD score and clinical type predict prognosis in hepatorenal syndrome: Relevance to liver transplantation. Hepatology (Baltimore, Md) 2005;41:1282-9.

15. Mindikoglu AL, Dowling TC, Weir MR, Seliger SL, Christenson RH, Magder LS. Performance of chronic kidney disease epidemiology collaboration creatinine-cystatin C equation for estimating kidney function in cirrhosis. Hepatology (Baltimore, Md) 2014;59:1532-42.

16. Mindikoglu AL, Weir MR. Current concepts in the diagnosis and classification of renal dysfunction in cirrhosis. Am J Nephrol 2013;38:345-54.

17. Larsson A, Malm J, Grubb A, Hansson LO. Calculation of glomerular filtration rate expressed in $\mathrm{mL} / \mathrm{min}$ from plasma cystatin $\mathrm{C}$ values in $\mathrm{mg} / \mathrm{L}$. Scand J Clin Lab Invest 2004;64:25-30.

18. Hoek FJ, Kemperman FA, Krediet RT. A comparison between cystatin C, plasma creatinine and the Cockcroft and Gault formula for the estimation of glomerular filtration rate. Nephrol Dialysis Transpl 2003;18:2024-31.

19. Inker LA, Schmid CH, Tighiouart H, et al. Estimating glomerular filtration rate from serum creatinine and cystatin C. N Engl J Med 2012;367:20-9.

20. Mehta RL, Kellum JA, Shah SV, et al. Acute Kidney Injury Network: Report of an initiative to improve outcomes in acute kidney injury. Crit Care 2007;11:R31.

21. Wong F, Nadim MK, Kellum JA, et al. Working party proposal for a revised classification system of renal dysfunction in patients with cirrhosis. Gut 2011;60:702-9.

22. Noronha Ferreira C, Rodrigues T, Cortez-Pinto H, et al. The new definition of acute kidney injury in patients with cirrhosis: A critical look. Gut 2012;61:1513.

23. Schepke M, Appenrodt B, Heller J, Zielinski J, Sauerbruch T. Prognostic factors for patients with cirrhosis and kidney dysfunction in the era of MELD: Results of a prospective study. Liver Int 2006;26:834-9

24. Salerno F, Gerbes A, Gines P, Wong F, Arroyo V. Diagnosis, prevention and treatment of hepatorenal syndrome in cirrhosis. Gut 2007;56:1310-8. 
25. Bernardi M, Caraceni P, Navickis RJ, Wilkes MM. Albumin infusion in patients undergoing large-volume paracentesis: A meta-analysis of randomized trials. Hepatology (Baltimore, Md) 2012;55:1172-81.

26. Gentilini P, Laffi G, La Villa G, Romanelli RG, Blendis LM. Ascites and hepatorenal syndrome during cirrhosis: Two entities or the continuation of the same complication? J Hepatol 1999;31:1088-97.

27. Moreau R, Lebrec D. Review article: Hepatorenal syndrome definitions and diagnosis. Aliment Pharmacol Ther 2004;(20 Suppl 3):24-8.

28. Runyon BA. Introduction to the revised American Association for the Study of Liver Diseases Practice Guideline management of adult patients with ascites due to cirrhosis 2012. Hepatology (Baltimore, Md) 2013;57:1651-3.

29. EASL clinical practice guidelines on the management of ascites, spontaneous bacterial peritonitis, and hepatorenal syndrome in cirrhosis. J Hepatol 2010;53:397-417.

30. Sort P, Navasa M, Arroyo V, et al. Effect of intravenous albumin on renal impairment and mortality in patients with cirrhosis and spontaneous bacterial peritonitis. N Engl J Med 1999;341:403-9.

31. Sigal SH, Stanca CM, Fernandez J, Arroyo V, Navasa M. Restricted use of albumin for spontaneous bacterial peritonitis. Gut 2007;56:597-9.

32. Francoz C, Glotz D, Moreau R, Durand F. The evaluation of renal function and disease in patients with cirrhosis. J Hepatol 2010;52:605-13.

33. Moreau R, Durand F, Poynard T, et al. Terlipressin in patients with cirrhosis and type 1 hepatorenal syndrome: A retrospective multicenter study. Gastroenterology 2002;122:923-30.

34. Prakash J, Mahapatra AK, Ghosh B, Arora P, Jain AK. Clinical spectrum of renal disorders in patients with cirrhosis of liver. Ren Fail 2011;33:40-6.

35. Gines P, Schrier RW. Renal failure in cirrhosis. N Engl Med 2009;361:1279-90.

36. Kamar N, Alric L, Izopet J, Rostaing L. Hepatitis C virus and kidney disease. Clin Res Hepatol Gastroenterol 2013:37:328-33.

37. Li P, Wei RB, Tang L, Wu J, Zhang XG, Chen XM. Clinical and pathological analysis of hepatitis $B$ virus-related membranous nephropathy and idiopathic membranous nephropathy. Clin Nephrol 2012;78:456-64.

38. Novak J, Julian BA. Sugars and alcohol: IgA-associated renal diseases in alcoholic cirrhosis. Kidney Int 2011;80:1252-4.

39. Tissandie E, Morelle W, Berthelot L, et al. Both IgA nephropathy and alcoholic cirrhosis feature abnormally glycosylated IgA1 and soluble CD89-IgA and IgG-IgA complexes: Common mechanisms for distinct diseases. Kidney Int 2011;80:1352-63.

40. Sancho J, Egido J, Sanchez-Crespo M, Blasco R. Detection of monomeric and polymeric IgA containing immune complexes in serum and kidney from patients with alcoholic liver disease. Clin Exp Immunol 1982;47:327-35.

41. Sinniah R. Heterogeneous IgA glomerulonephropathy in liver cirrhosis. Histopathology 1984;8:947-62.

42. Kalaitzakis E, Rosengren A, Skommevik T, Bjornsson E. Coronary artery disease in patients with liver cirrhosis. Dig Dis Sci 2010;55:467-75.

43. Tiukinhoy-Laing SD, Rossi JS, Bayram M, et al. Cardiac hemodynamic and coronary angiographic characteristics of patients being evaluated for liver transplantation. Am J Cardiol 2006;98:178-81.

44. Letiexhe MR, Scheen AJ, Gerard PL, et al. Insulin secretion, clearance, and action on glucose metabolism in cirrhotic patients. J Clin Endocrinol Metabol 1993;77:1263-8.

45. Standards of medical care in diabetes - 2013. Diabet Care 2013;36(Suppl 1):S11-66.

46. Gross JL, de Azevedo MJ, Silveiro SP, Canani LH, Caramori ML, Zelmanovitz T. Diabetic nephropathy: Diagnosis, prevention, and treatment. Diabetes Care 2005;28:164-76.

47. Sumida K, Ubara Y, Hoshino J, et al. Hepatitis C virus-related kidney disease: Various histological patterns. Clin Nephrol 2010;74:446-56.

48. Ramesh Prasad GV, Bastacky S, Johnston JR. Diabetic nephropathy with concurrent hepatitis $\mathrm{C}$ virus infection related membranoproliferative glomerulonephritis. Clin Nephrol 1999;51:50-3.

49. Zhuo L, Ren W, Li W, Zou G, Lu J. Evaluation of renal biopsies in type 2 diabetic patients with kidney disease: $\mathrm{A}$ clinicopathological study of 216 cases. Int Urol Nephrol 2013;45:173-9.

50. Hironaka K, Makino H, Ikeda S, Haramoto T, Ota Z. Nondiabetic renal disease complicating diabetic nephropathy. J Diabetes Complications 1991;5:148-9.

51. Yaqub S, Kashif W, Hussain SA. Non-diabetic renal disease in patients with type-2 diabetes mellitus. Saudi J Kidney Dis Tranpl 2012;23:1000-7.

52. Gonzalez Suarez ML, Thomas DB, Barisoni L, Fornoni A. Diabetic nephropathy: Is it time yet for routine kidney biopsy? World J Diabetes 2013;4:245-55.

53. Hamdi A, Hajage D, Van Glabeke E, et al. Severe post-renal acute kidney injury, post-obstructive diuresis and renal recovery. BJU Int 2012;110(11 Pt C):E1027-34.

54. Khan IH, Catto GR, Edward N, Macleod AM. Acute renal failure: Factors influencing nephrology referral and outcome. QJM 1997;90:781-5.

55. Liano F, Pascual J. Epidemiology of acute renal failure: A prospective, multicenter, community-based study. Madrid Acute Renal Failure Study Group. Kidney Int 1996;50:811-8. 


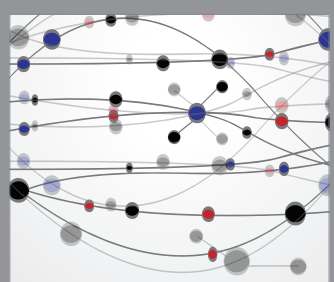

The Scientific World Journal
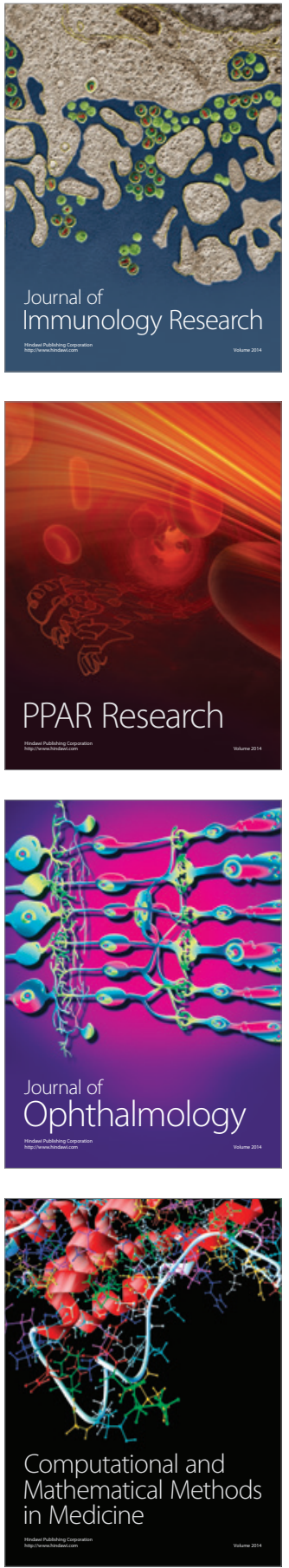

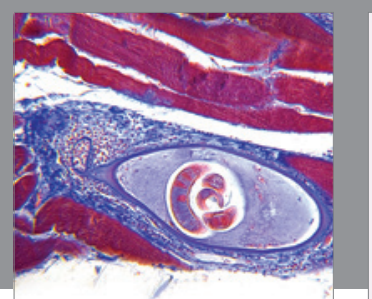

Gastroenterology Research and Practice

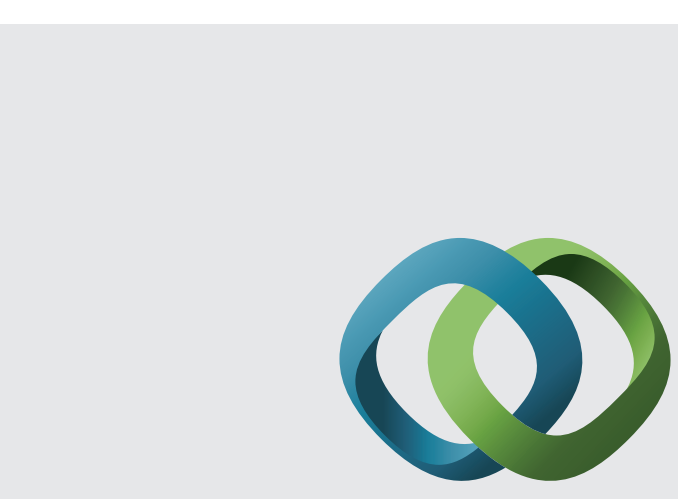

\section{Hindawi}

Submit your manuscripts at

http://www.hindawi.com
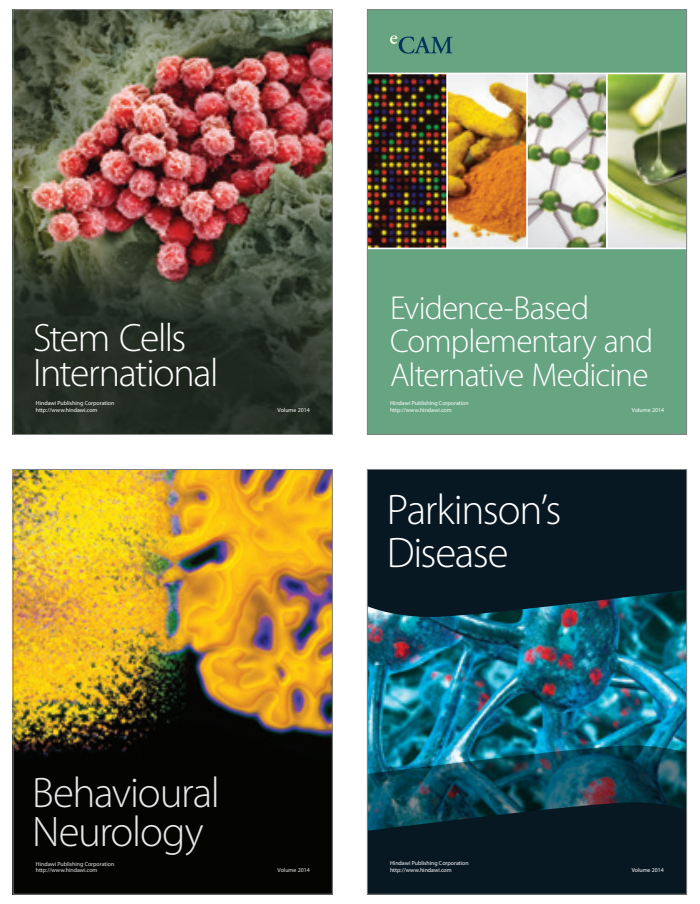
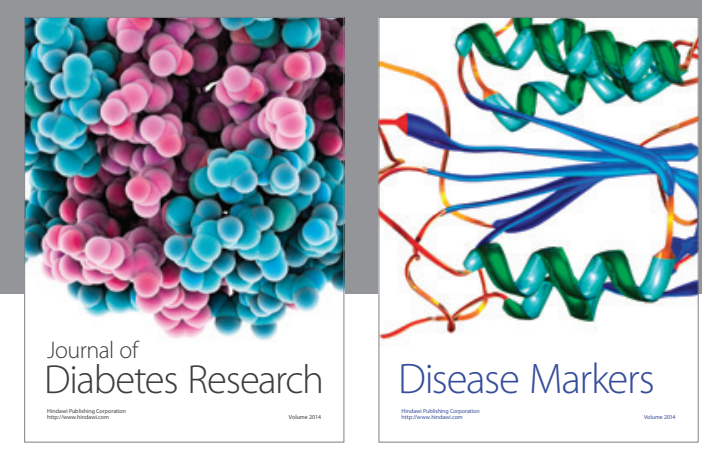

Disease Markers
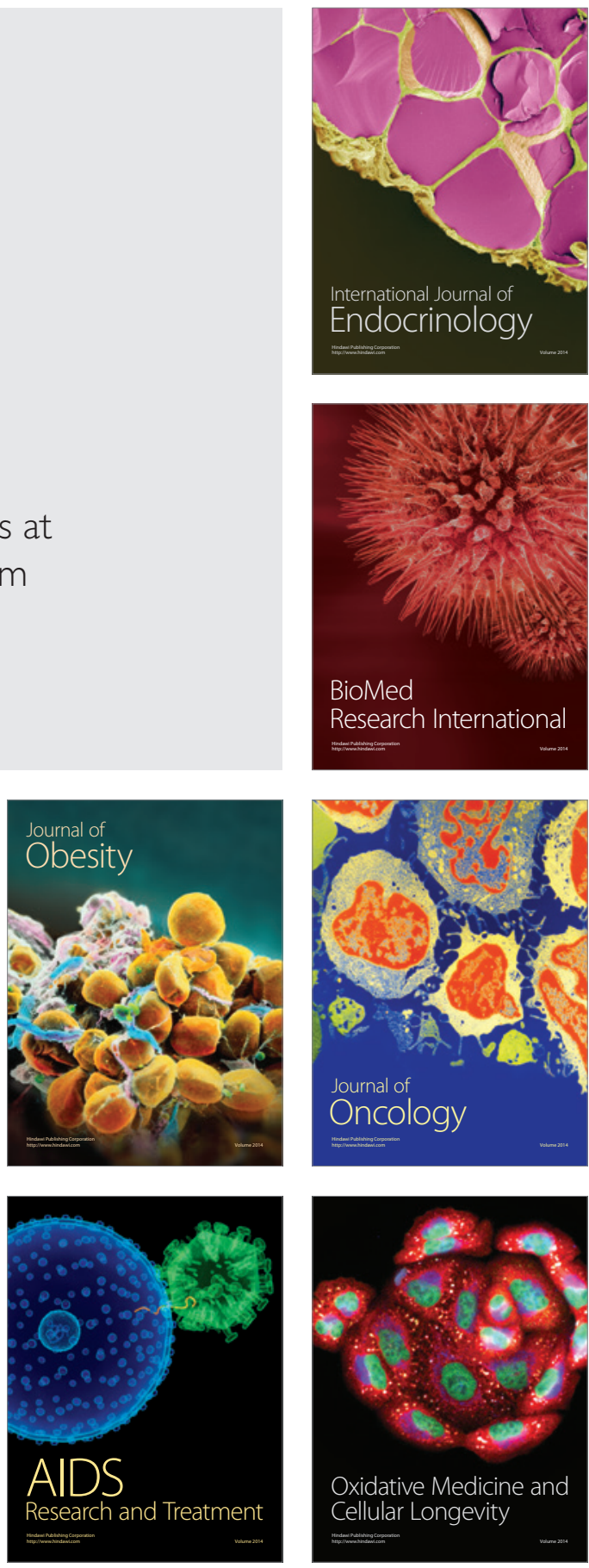